\title{
A minimal, statistical model for the surface albedo of Vestfonna ice cap, Svalbard
}

\author{
M. Möller \\ Department of Geography, RWTH Aachen University, Templergraben 55, Aachen, Germany \\ Correspondence to: M. Möller (marco.moeller@geo.rwth-aachen.de)
}

Received: 22 February 2012 - Published in The Cryosphere Discuss.: 12 March 2012

Revised: 31 August 2012 - Accepted: 31 August 2012 - Published: 26 September 2012

\begin{abstract}
The ice cap Vestfonna is located in northeastern Svalbard and forms one of the largest ice bodies of the Eurasian Arctic. Its surface albedo plays a key role in the understanding and modelling of its energy and mass balance. The principle governing factors for albedo evolution, i.e. precipitation and air temperature and therewith snow depth and melt duration, were found to vary almost exclusively with terrain elevation throughout the ice cap. Hence, surface albedo can be expected to develop a comparable pattern. A new statistical model is presented that estimates this mean altitudinal albedo profile of the ice cap on the basis of a minimal set of meteorological variables on a monthly resolution. Model calculations are based on a sigmoid function of the artificial quantity rain-snow ratio and a linear function of cumulative snowfall and cumulative positive degree days. Surface albedo fields of the MODIS snow product MOD10A1 from the period March to October in the years 2001-2008 serve as a basis for both calibration and cross-validation of the model. The meteorological model input covers the period September 2000 until October 2008 and is based on ERA-Interim data of a grid point located close to the ice cap. The albedo model shows a good performance. The root mean square error between observed and modelled albedo values along the altitudinal profile is $0.057 \pm 0.028$ (mean \pm one standard deviation). The area weighted mean even reduces to a value of 0.054 . Distinctly higher deviations $(0.07-0.09)$ are only present throughout the very lowest and uppermost parts of the ice cap that are either small in area or hardly affected by surface melt. Thus, the new, minimal, statistical albedo model presented in this study is found to reproduce the albedo evolution on Vestfonna ice cap on a high level of accuracy and is thus suggested to be fully suitable for further application in broader energy or mass-balance studies of the ice cap.
\end{abstract}

\section{Introduction}

Glaciers and ice caps (GIC) outside Greenland and Antarctica contributed $0.028 \mathrm{~m}(\sim 16 \%)$ to 20th century sea-level rise (Raper and Braithwaite, 2006). In the period 1961-1990 the share of Arctic GIC in this sum was about one fourth (Kaser et al., 2006). Moreover, the Arctic ice masses are located in the region of highest predicted air temperature increase during the coming decades (Rinke and Dethloff, 2008) and can thus be expected to further increase their contribution in the future. The Arctic can therefore be considered as a major source region for present and future GIC induced sealevel rise and knowledge on Arctic glacier mass balance thus emerges as a key factor in understanding current sea levelrise dynamics.

On Arctic glaciers, the major source for melt energy is net shortwave radiation (e.g. Arendt, 1999; Winther et al., 2003), and thus robust albedo parameterizations play a key role in calculations of their energy and mass balance. Most calculation schemes for the surface albedo of glaciers are run on high temporal resolution considering age, depth, density and temperature of the snow layer or accumulated melt on the glacier surface as input variables (e.g. Brock et al., 2000; Essery et al., 2005). To apply these kinds of albedo models on large Arctic ice caps it would be necessary to additionally account for snowdrift influences on a highly resolved scale, as snowdrift frequently disturbs the in-situ developed surface-albedo pattern in these environments. For Vestfonna ice cap, the important role of snowdrift was already noted during early expeditions in the first half of the 20th century (Ahlmann, 1933; Moss, 1938). The frequent occurrence of snowdrift on the ice cap is based on the prevalence of high wind speeds. Claremar et al. (2012) report a predominant range of $5-15 \mathrm{~m} \mathrm{~s}^{-1}$ from in-situ measurements which is well 
in the region of threshold wind speeds for snowdrift initialisation (e.g. Mahesh et al., 2003).

However, implementing a snowdrift-modelling scheme into an albedo-model architecture would increase computational costs many times over. This in turn would probably prohibit any application of such a complex albedo model in long-term studies. As, moreover, small scale spatiotemporal variability of most meteorological parameters are poorly known in Arctic environments, the spatial distribution of surface albedo on Arctic ice caps can anyway only be reliably treated on a less highly resolved scale. Hence, under the conditions present in the study region, a statistically based albedo model without a discrete, daily-resolution, temporal parameter is needed that, in addition, also accounts for snowdrift-related influences.

The surface albedo on Vestfonna ice cap shows a characteristic pattern and evolution throughout a mass-balance year. Remote sensing-based observations employed in this article show that it varies mainly with terrain elevation and thus reflects the combined influences of air temperature and both liquid and solid precipitation on the glacier surface. This fact facilitates the development of a statistical albedo calculation scheme that uses altitudinal profiles of the most easily accessible meteorological variables as input. Due to its empirical basis it thus avoids the drawbacks of more physically oriented modelling approaches.

The aim of this study is to describe a new parameterization scheme for the surface albedo of large Arctic ice caps. The presented albedo model has a monthly temporal resolution, while its spatial resolution is limited to altitudinal variability only. It is thus especially designed for application in long-term mass-balance studies like future projections where calculations with high spatiotemporal resolution are difficult or even impossible due to data limitations.

The model is based on a minimal number of meteorological input variables that reflect both, present weather conditions within each month and a long-term memory since the start of the corresponding mass-balance year. Monthly weather conditions are represented by altitudinal profiles of rain-snow ratio and thus implicitly include information about both air temperature and precipitation. The long-term memory is represented by cumulative positive degree days as well as cumulative snowfall sums since the start of the massbalance year in September.

The study employs Terra MODIS (Moderate Resolution Imaging Spectroradiometer) derived surface albedo data as well as ERA-Interim based air temperature and precipitation data covering the period 2000-2008 for model setup. These data were provided by Möller et al. (2011a). Calibration and validation of the model is done using cross-validation techniques following Kohavi (1995).

After introducing the study area (Sect. 2), the article describes the data basis used for model calibration with special emphasis on the preparation of the input datasets (Sect. 3). Section 4 then outlines the methodology of the new albedo model followed by the results of the cross-validation procedure used for model calibration and a comprehensive discussion of model sensitivity and performance.

\section{Study area}

Vestfonna ice cap is located on the island Nordaustlandet in the northeastern Svalbard archipelago (Fig. 1). Its surface area of $\sim 2340 \mathrm{~km}^{2}$ in 2005 (Braun et al., 2011) that covers elevations between sea level and $\sim 630 \mathrm{~m}$ a.s.l. makes it one of the largest ice masses of the Eurasian Arctic. The relief of the generally flat surface of the ice cap is dominated by two main ridges, one of them stretching W-E and the other N$\mathrm{S}$. Its highest point is located close to the conjunction of the two ridges in the eastern central part of the ice cap (Fig. 1). In between these ridges, Vestfonna is dominated by large outlet glacier basins and land-terminating ice lobes.

The climate of the Svalbard region is governed by the contrasting influences of different air masses, cold and dry Arctic air coming from the north and warm and humid air coming from the northern Atlantic Ocean (Svendsen et al., 2002). The dominating ocean currents in the region also reflect this contrast. The warm West Spitsbergen Current influences the western coastal regions of Spitsbergen (Walczowski and Piechura, 2011) while the eastern parts of the archipelago are mainly under the influence of cold Arctic ocean currents (Loeng, 1991).

On Nordaustlandet the climatic setting is governed by easterly weather systems originating in the Barents Sea region (Taurisano et al., 2007). They provide the major moisture source for precipitation (Førland et al., 1997). This means that Vestfonna is mostly located in the lee of the larger and higher ice cap Austfonna that covers the eastern part of Nordaustlandet. Precipitation sums are thus generally smaller on Vest- than on Austfonna (Hagen et al., 1993) and they show considerable variability between different years (Beaudon et al., 2011), while the spatial distribution over the ice cap is almost entirely determined by terrain elevation (Möller et al., 2011b). Air temperatures in the study region show pronounced annual cycles. The mean summer air temperature at $370 \mathrm{~m}$ a.s.l. on Vestfonna is $\sim 0^{\circ} \mathrm{C}$ with most of the days showing values between $-3{ }^{\circ} \mathrm{C}$ and $+3{ }^{\circ} \mathrm{C}$ (Möller et al., 2011b). Hence, melt conditions frequently extent over the entire ice cap (Rotschky et al., 2011). Melting generally starts in late June, reaches its maximum during mid and late July and then declines until end of August (Möller et al., 2011a). Due to the highly maritime setting of the study area, air temperatures show distinctly higher intra-monthly variability during winter. Daily means vary in the range $-24^{\circ} \mathrm{C}$ to $-4{ }^{\circ} \mathrm{C}$ (Möller et al., 2011b). 


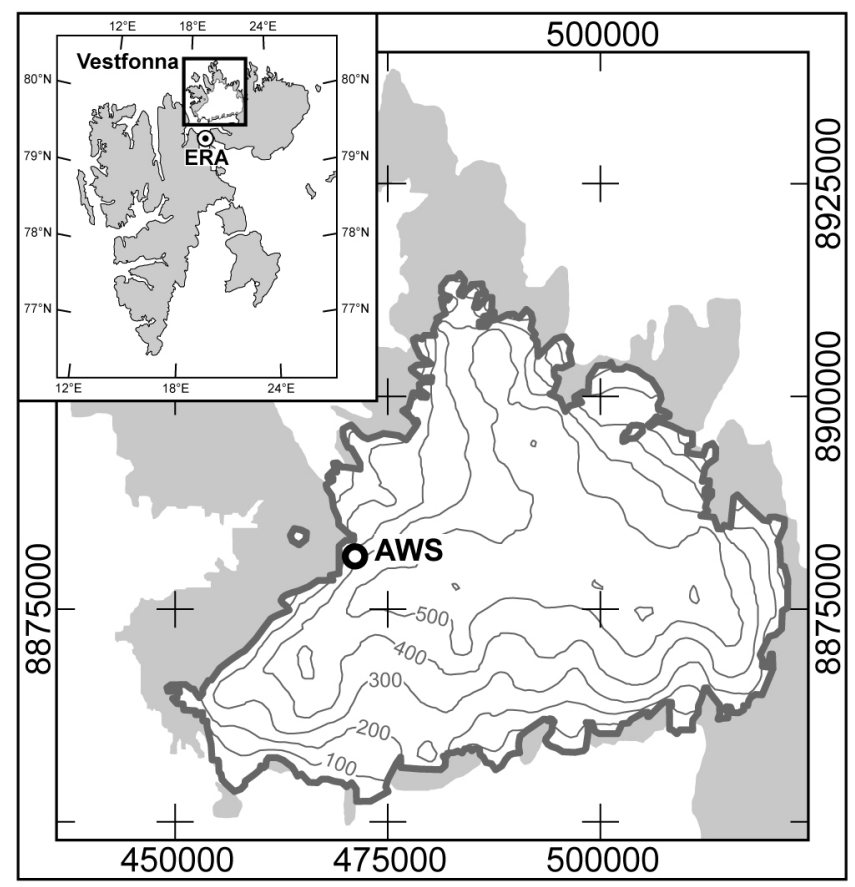

Fig. 1. Overview map of the study area. Coordinates refer to UTM (Universal Transverse Mercator) zone 34N. Contour spacing on the ice cap is $100 \mathrm{~m}$ starting at sea level. The circle (AWS) marks the location of the automatic weather station. The inset on the upper left shows the location of Vestfonna ice cap in the Svalbard Archipelago. The circle (ERA) marks the location of the ERAInterim grid point.

\section{Data preparation}

This study requires surface-elevation data and monthly mean albedo fields of Vestfonna ice cap. Meteorological data of air temperature and precipitation as well as local lapse rates are also needed. All data preparation in this study is done in a model domain with a regular $500 \mathrm{~m}$ grid that serves as a basis for deriving the altitudinal gradients of the input variables.

\subsection{Terrain data}

The outline of Vestfonna ice cap is digitized from a Terra ASTER (Advanced Spaceborne Thermal Emission and Reflection Radiometer) scene dating from 17 August 2000 (EOS Data Gateway Granule ID: SC:ASTL1B 0008-12:36:0010269001). Surface elevations are based on the ASTER Global Digital Elevation Model (GDEM). Limited areas of data voids and isolated elevation outliers in the central parts of the ice cap are interpolated on the basis of surrounding grid cells. Glacier outlines and the surface elevation grid are co-registered with the $500 \mathrm{~m}$ grid of the model domain using standard resampling techniques. Finally, a digital elevation model (DEM) of the ice-cap surface is created by masking the resampled GDEM to the glacier area using the digitized outlines.

\subsection{Albedo profiles}

The monthly mean albedo profiles are based on the MODIS snow product MOD10A1 version 5 (Hall et al., 2002; Hall and Riggs, 2007) of the period 2001-2008. This product is regularly generated from acquisitions of the polar orbiting satellite Terra that cover the study area ten times each day. The albedo information contained in the snow product is derived from the scene acquired closest to nadir. From the original, daily albedo fields with a spatial resolution of $500 \mathrm{~m}$, monthly mean albedo fields are calculated. Pixels not holding any albedo information due to cloud cover or non-classifiable characteristics are left out during the averaging procedure. This results in a mean update frequency of albedo information of 2.9 days over the ice cap (Möller et al., 2011a). No MOD10A1 datasets are available for the study area during the period of polar night. Accordingly, albedo fields are only created for the eight-months period March to October. Finally, a total of 64 mean altitudinal profiles of monthly surface albedo along a set of 31 individual $20 \mathrm{~m}$ elevation bins are calculated over the ice-cap DEM.

The accuracy of the daily MODIS albedo data is assessed by comparison with in-situ measurements at an automatic weather station (AWS) located on the northwestern slope of Vestfonna (Fig. 1). For the period May 2008 to July 2009 a root mean square error (RMSE) of 0.12 is obtained (Möller et al., 2011a). As considerable parts of this error can be attributed to the fact that the observations at the AWS only cover a very limited part of the corresponding, much larger MOD10A1 grid cell (Stroeve et al., 2006), the MODIS data are assumed to adequately reproduce the surface conditions on the ice cap. However, it has to be borne in mind that the MODIS albedo observations are biased towards days with clear-sky conditions. This implies slightly lower albedo values as snow albedo generally increases with cloud coverage (Wiscombe and Warren, 1980).

Wang and Zender (2010b) describe a systematic bias in MODIS albedo data depending on solar zenith angle and present a related correction algorithm (Wang and Zender, 2010a). However, their studies refer to the MCD43 instead of the MOD10 dataset family and thus to a dataset that is based on substantially different processing algorithms and that consists of different final products (Stroeve et al., 2006). While MCD43 datasets provide black sky albedo (BSA) and white sky albedo (WSA) separately, the MOD10 datasets only contain a linear combination of both. Stroeve et al. (2006) evaluate the performance of both albedo products and show the existence of a mean bias of $+0.04 /+0.08$ when comparing MOD10 albedo values to MCD43 BSA/WSA values. They further show that the MOD10 albedos exhibit better consistency with in-situ AWS measurements. The considerable negative bias of the MCD43 albedos is also documented for a site in northern Greenland with a similar latitude as Vestfonna ice cap (Schaaf et al., 2011). It is, however, only evident in periods with a local noon zenith angle of above $\sim 70^{\circ}$. 
This means that in periods with a lower zenith angle even the more error-prone MCD43 albedos form a reliable representation of in-situ conditions and hence the MOD10 data can be expected to do so all the more.

Taken together, the MOD10A1 albedos can be assumed to be fully eligible for usage as calibration and validation datasets in the here-presented modelling study. The noon zenith angle at Vestfonna is below $70^{\circ}$ from mid April to end of August, i.e. during the entire ablation season where accurate albedo information is crucial for mass balance modelling. Besides that, no characteristic annual evolution of the bias between MOD10A1 and AWS albedo as described by Wang and Zender (2010a; 2010b) is identifiable in the study area. Hence, no corrections of the MODIS albedo data are carried out. It has, nevertheless, to be borne in mind that the existence of a minor seasonal bias could still not be ruled out completely. This has to be accounted for when applying the albedo-modelling scheme during mass balance studies by considering appropriate error assumptions.

\subsection{Meteorological data}

All meteorological data used in this study are based on daily ERA-Interim reanalysis data of the grid point located at $79.5^{\circ} \mathrm{N} 19.5^{\circ} \mathrm{E}$ (Fig. 1); data cover the period September 2000 to October 2008. The original air temperature and precipitation data are statistically downscaled to fit local conditions on the ice cap (Möller et al., 2011a). From these data, altitudinal profiles of monthly means of positive degree days, snowfall and rain-snow ratio are created using lapse rates given by Möller et al. (2011a).

\subsubsection{Positive degree days}

The original, daily ERA-Interim air temperatures are downscaled according to Möller et al. (2011a) by using varianceinflation techniques (Huth, 1999; Karl et al., 1990; Von Storch, 1999). From the downscaled daily data monthly means are calculated. The distribution over altitude is done using a constant linear lapse rate of $7.0 \mathrm{~K} \mathrm{~km}^{-1}$ (Möller et al., 2011a).

Positive degree days were calculated according to Braithwaite (1984) and Möller and Schneider (2010) based on the probability density function of air temperature of month $i$ that is defined as

$p_{i}\left(T_{z}\right)=\frac{1}{\sigma_{T, m} \sqrt{2 \pi}} \exp \left(-\frac{1}{2}\left(\frac{T_{z}-\overline{T_{i, z}}}{\sigma_{T, m}}\right)^{2}\right)$

with $\sigma_{T, m}$ being the standard deviation of air temperature that is characteristic for a specific month $m(1,2, \ldots, 12)$ of the annual cycle (Table 1), $T_{z}$ the air temperature at elevation $z$ and $\overline{T_{i, z}}$ the mean air temperature of month $i$ at elevation $z$. Based on the integral over the positive interval of Equation 1 , the profile of positive degree days in month $i\left(\Phi_{\mathrm{pdd}, i}\right)$ is
Table 1. Mean standard deviations of daily air temperature $\left(\sigma_{T, m}\right)$ within the specific months $m$ of the annual cycle. Values are longterm means that are calculated from the downscaled daily ERAInterim air temperatures of the period 2000-2008. Unit is ${ }^{\circ} \mathrm{C}$.

\begin{tabular}{ccc}
\hline Month & $m$ & $\sigma_{T, m}$ \\
\hline Jan & 1 & 7.39 \\
Feb & 2 & 5.88 \\
Mar & 3 & 5.44 \\
Apr & 4 & 5.96 \\
May & 5 & 4.21 \\
Jun & 6 & 2.75 \\
Jul & 7 & 2.03 \\
Aug & 8 & 3.17 \\
Sep & 9 & 3.94 \\
Oct & 10 & 4.70 \\
Nov & 11 & 4.74 \\
Dec & 12 & 6.20 \\
\hline
\end{tabular}

calculated according to

$\Phi_{\mathrm{pdd}, i}(z)=N_{i} \overline{T_{i, z}^{+}} \int_{0}^{\infty} p_{i}\left(T_{z}\right) \mathrm{d} T_{z}$

with $N_{i}$ being the number of days of month $i$ and $\overline{T_{i, z}^{+}}$the mean over the positive daily air temperatures of month $i$ at elevation $z$ that is calculated by solving the following equation for $\overline{T_{i, z}^{+}}$

$\int_{0}^{\overline{T_{i, z}^{+}}} p_{i}\left(T_{z}\right) \mathrm{d} T_{z}-\int_{\frac{\int_{i, z}^{+}}{\infty}}^{\infty} p_{i}\left(T_{z}\right) \mathrm{d} T_{z}=0$.

Finally, the profile of cumulative positive degree days $\left(\Phi_{\mathrm{cpdd}, i}\right)$ in month $i$ is calculated as the sum over the monthly profiles of positive degree days since the beginning of the corresponding mass-balance year according to

$\Phi_{\mathrm{cpdd}, i}(z)=\sum_{k} \Phi_{\mathrm{pdd}, k}(z)$.

In this equation, $k$ is the set of individual months between September of the previous year and month $i$ of the present year.

\subsubsection{Snowfall and rain-snow ratio}

The original, daily ERA-Interim precipitation amounts are summed up to monthly values. The precipitation sum in month $i$ is then distributed over altitude using quadratic scaling according to an index function of elevation $(z)$. This function was derived by Möller et al. (2011a) on the basis of extensive in-situ snow water equivalent measurements across 
the ice cap that cover four consecutive accumulation seasons (Möller et al., 2011b). It thus already accounts for the effects of snowdrift-related mass transfer across the ice cap and is given as

$$
P_{i}(z)=P_{i, 0}\left(9.9 \times 10^{-6} z^{2}+7.9 \times 10^{-3} z+1\right) .
$$

In this equation $P_{i, 0}$ is the original ERA-Interim precipitation of month $i$. It is set to represent sea-level conditions by forcing the intercept of Eq. (5) to one. The result $\left(P_{i}\right)$ is the scaled precipitation profile. The corresponding profile of the proportion of snowfall $\left(\Phi_{\mathrm{sf}, i}\right)$ in month $i$ depends on the probability of negative air temperatures that can be derived from Eq. (1). It is calculated as

$\Phi_{\mathrm{sf}, i}(z)=P_{i}(z) \int_{-\infty}^{0} p_{i}\left(T_{z}\right) \mathrm{d} T_{z}$.

The profile of cumulative snowfall sum $\left(\Phi_{\mathrm{csf}, i}\right)$ in month $i$ is calculated analogue to Eq. (4) as

$\Phi_{\mathrm{csf}, i}(z)=\sum_{k} \Phi_{\mathrm{sf}, k}(z)$.

The profile of rain-snow ratio $\left(\Phi_{\mathrm{rsr}, i}\right)$ in month $i$ is calculated on the basis of the overall precipitation-sum profile Eq. (5) and the profile of the proportion of snowfall Eq. (6) according to

$\Phi_{\mathrm{rsr}, i}(z)=\frac{P_{i}(z)-\Phi_{\mathrm{sf}, i}(z)}{\Phi_{\mathrm{sf}, i}(z)}$.

\section{Model description}

The presented model calculates mean monthly profiles of the surface albedo of Vestfonna ice cap on the basis of different meteorological input variables using multiple, non-linear regression techniques implemented in a two-step procedure. Meteorological variables are given as altitudinal profiles and the fitting parameters of the model as functions of terrain elevation. They therewith represent the specific altitudinal variability that characterises the surface-albedo pattern on the ice cap.

Calibration and implicit validation of the model is done using cross-validation techniques. Uncertainty considerations that serve as a basis for a quality assessment regarding the modelled surface albedo are also derived from the crossvalidation.

\subsection{Fundamentals}

The albedo of a glacier surface is influenced by a variety of factors that show a complex interaction with each other. Primarily, it depends on the type of the surface, i.e. snow cover or bare glacier ice. In general, snow albedo is more variable than ice albedo. Ageing of the snow cover that involves snow-grain metamorphism results in a continuous decrease of snow albedo (Jordan et al., 2008). This process is amplified by melt conditions and positive air temperatures as well as rainfall can thus be considered to have a major impact on snow albedo. Fresh snowfall on the other hand results in a sudden albedo increase.

To combine the counteracting influences of air temperature, rain- and snowfall into one parameter, an artificial meteorological variable called rain-snow ratio is introduced. Air temperature is assumed to decrease with terrain elevation according to a constant gradient. Hence, the proportion of rainfall in the total precipitation sum shows a decrease with terrain elevation while the proportion of snowfall increases correspondingly. However, precipitation sums in total increase with terrain elevation according to an increasing gradient, Eq. (5), and the transition between rain and snow proportions is also non-linear, Eq. (6). Taken together, these characteristics thus result in a non-linear relation between rain-snow ratio and snow albedo (Fig. 2).

The temporal evolution of glacier-surface albedo is largely influenced by snow depth, i.e. by the amounts of snowfall during the winter season, as well as by cumulative length and intensity of melt conditions that have already been effective since the beginning of the melt season. These variables mainly control the timing of bare ice exposure.

However, the response of surface albedo to the given variables is not uniform. It differs along the elevation profile of the ice cap due to the complexity of snowdrift influences. These influences affect snow depth and surface albedo in different ways and are thus represented on different time scales in both the climate data used for driving the model and the albedo data used for model calibration and validation. Moreover, they constantly vary in intensity due to curvature variations over the ice cap. Regions with a convex terrain foster erosion while deposition mainly occurs throughout regions with a concave terrain.

The total of all snowdrift-related mass transfers over the ice cap within each accumulation season is captured in the snow pit-derived precipitation profile and thus in the profiles of the variables rain-snow ratio and cumulative snowfall (long-term scale). When looking at each snowdrift event separately, this means that the outcome of all mass transfer-related influences of this event is covered by the precipitation-based input datasets. In contrast to that, the MODIS-derived albedo profiles capture the transient surface albedo change at a specific instant during each snowdrift event (short-term scale). However, before being included in the calibration procedure these short-term albedo variations are averaged over one month to fit model resolution.

Hence, the effects of snowdrift on rain-snow ratio and cumulative snowfall are indeed implicitly accounted for during model calibration, but deviations between modelled and observed surface albedo might nevertheless occur as a result of snowdrift-related, short-term albedo changes that are induced by the temporal discrepancies between model 
Table 2. Description of the parameter functions $\theta_{1-4}(z)$ and $\psi_{1-3}(z)$ of the albedo model (Fig. 3) that are employed in Eqs. (10) and (11). The parameters of the parameter functions $(a, b, c, d)$ are given for the FAM (mean \pm one standard deviation) and the IAM (value in parenthesis). The parameter functions are fitted to the respective individual parameter values that are obtained for the 31 elevation bins. The coefficients of determination $\left(R^{2}\right)$ of the parameter functions are also given for the FAM and for the IAM (value in parenthesis).

\begin{tabular}{|c|c|c|c|c|c|}
\hline Parameter function & $a$ & $b$ & $c$ & $d$ & $R^{2}$ \\
\hline$\theta_{1}(z)=a z+b$ & $\begin{array}{l}-3.43 \pm 1.11 \times 10^{-5} \\
\left(-3.53 \times 10^{-5}\right)\end{array}$ & $\begin{array}{l}9.07 \pm 0.05 \times 10^{-1} \\
\left(9.07 \times 10^{-1}\right)\end{array}$ & n.a. & n.a. & $\begin{array}{l}0.76 \\
(0.60)\end{array}$ \\
\hline$\theta_{2}(z)=a z^{b}+c$ & $\begin{array}{l}3.02 \pm 0.79 \times 10^{-2} \\
\left(3.00 \times 10^{-2}\right)\end{array}$ & $\begin{array}{l}4.36 \pm 0.38 \times 10^{-1} \\
\left(4.32 \times 10^{-1}\right)\end{array}$ & $\begin{array}{l}1.77 \pm 0.15 \times 10^{-1} \\
\left(1.78 \times 10^{-1}\right)\end{array}$ & n.a. & $\begin{array}{l}0.99 \\
(0.99)\end{array}$ \\
\hline$\theta_{3}(z)=a+b z+c z^{2}$ & $\begin{array}{l}2.98 \pm 0.01 \times 10^{-1} \\
\left(2.99 \times 10^{-1}\right)\end{array}$ & $\begin{array}{l}3.00 \pm 0.85 \times 10^{-5} \\
\left(2.66 \times 10^{-5}\right)\end{array}$ & $\begin{array}{l}-6.63 \pm 1.20 \times 10^{-8} \\
\left(-6.07 \times 10^{-8}\right)\end{array}$ & n.a. & $\begin{array}{l}0.69 \\
(0.88)\end{array}$ \\
\hline$\theta_{4}(z)=a+b z+c z^{2}+d z^{3}$ & $\begin{array}{l}4.22 \pm 0.18 \times 10^{-1} \\
\left(4.26 \times 10^{-1}\right)\end{array}$ & $\begin{array}{l}1.90 \pm 0.35 \times 10^{-3} \\
\left(1.83 \times 10^{-3}\right)\end{array}$ & $\begin{array}{l}-6.23 \pm 1.11 \times 10^{-6} \\
\left(-5.94 \times 10^{-6}\right)\end{array}$ & $\begin{array}{l}5.95 \pm 1.19 \times 10^{-9} \\
\left(5.62 \times 10^{-9}\right)\end{array}$ & $\begin{array}{l}0.81 \\
(0.74)\end{array}$ \\
\hline$\psi_{1}(z)=a z+b$ & $\begin{array}{l}-1.18 \pm 0.10 \times 10^{-4} \\
\left(-1.16 \times 10^{-4}\right)\end{array}$ & $\begin{array}{l}5.68 \pm 0.63 \times 10^{-2} \\
\left(5.62 \times 10^{-2}\right)\end{array}$ & n.a. & n.a. & $\begin{array}{l}0.91 \\
(0.92)\end{array}$ \\
\hline$\psi_{2}(z)=a z^{b}+c$ & $\begin{array}{l}3.34 \pm 0.43 \times 10^{-3} \\
\left(3.44 \times 10^{-3}\right)\end{array}$ & $\begin{array}{l}9.79 \pm 0.69 \times 10^{-2} \\
\left(9.52 \times 10^{-2}\right)\end{array}$ & $\begin{array}{l}-6.06 \pm 0.59 \times 10^{-3} \\
\left(-6.17 \times 10^{-3}\right)\end{array}$ & n.a. & $\begin{array}{l}0.98 \\
(0.96)\end{array}$ \\
\hline$\psi_{3}(z)=a+b z+c z^{2}$ & $\begin{array}{l}3.37 \pm 0.13 \times 10^{-4} \\
\left(3.33 \times 10^{-4}\right)\end{array}$ & $\begin{array}{l}9.31 \pm 2.17 \times 10^{-7} \\
\left(9.62 \times 10^{-7}\right)\end{array}$ & $\begin{array}{l}-3.16 \pm 0.36 \times 10^{-9} \\
\left(-3.21 \times 10^{-9}\right)\end{array}$ & n.a. & $\begin{array}{l}0.97 \\
(0.98)\end{array}$ \\
\hline
\end{tabular}

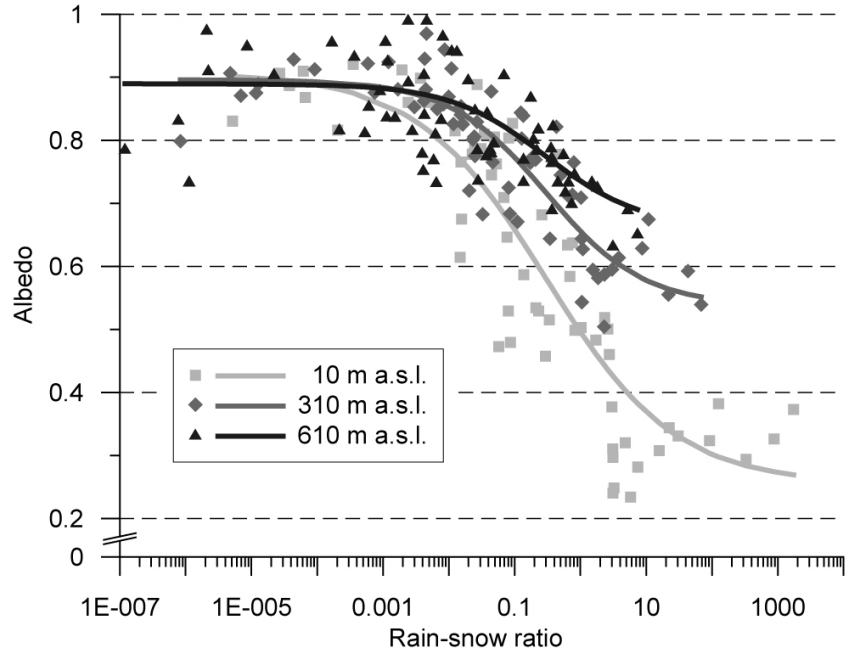

Fig. 2. Rain-snow ratio versus MODIS-derived surface albedo for three selected $20 \mathrm{~m}$ elevation bins. Bins are centred at the elevations given in the legend. Given data pairs refer to the period MarchOctober of the years 2001-2008. Lines represent the fitted sigmoid functions according to Eq. (10).

resolution and MODIS observations. These temporal discrepancies are, however, likewise influenced by the different intensities of snowdrift processes at different elevations of the ice cap, i.e. highest accumulation along its fringe and most intensive erosion throughout its uppermost parts. To account for this fact, the model architecture does not feature space-constant parameters but parameters that are calibrated as a function of elevation (Fig. 3). Accordingly, the model shows different responses of surface albedo to similar climate forcing at different elevations of the ice cap.
Taken together, this means that the model is conditioned to present ice cap geometry. Therefore, the assumption of stationarity of present conditions has to be made for any past or future application of the model.

\subsection{Initial setup}

Model setup and initial calibration are done based on monthly albedo profiles of the period 2001-2008 with the months March to October represented in each year. In total, this makes a data basis of 64 individual months. Profiles of meteorological data cover a slightly longer period and show no wintertime data gaps. Coverage comprises the period September 2000 to October 2008. This is done in order to facilitate the calculation of cumulative meteorological data for the entire calibration period.

For model calibration the profiles are represented by a series of static $20 \mathrm{~m}$ elevation bins. To cover the entire set of surface elevations present on the ice cap, 31 of these bins are employed. For each bin a mean terrain elevation is calculated on the basis of the DEM. The meteorological data for each bin are then calculated according to these mean elevations. The albedo data for each bin are averaged over the corresponding grid cells of the model domain.

According to the described fundaments, the model initially calculates the albedo profile as a sigmoid function of the mean monthly profile of rain-snow ratio $\left(\Theta_{i}(z)\right)$. The profile of remaining residuals is then approximated by a linear function $\left(\Psi_{i}(z)\right)$ of profiles of cumulative snowfall and cumulative positive degree days since the beginning of the corresponding mass-balance year, i.e. the previous September. The albedo profile $\left(\alpha_{i}(z)\right)$ of month $i$ is thus calculated as

$\alpha_{i}(z)=\Theta_{i}(z)-\Psi_{i}(z)$ 


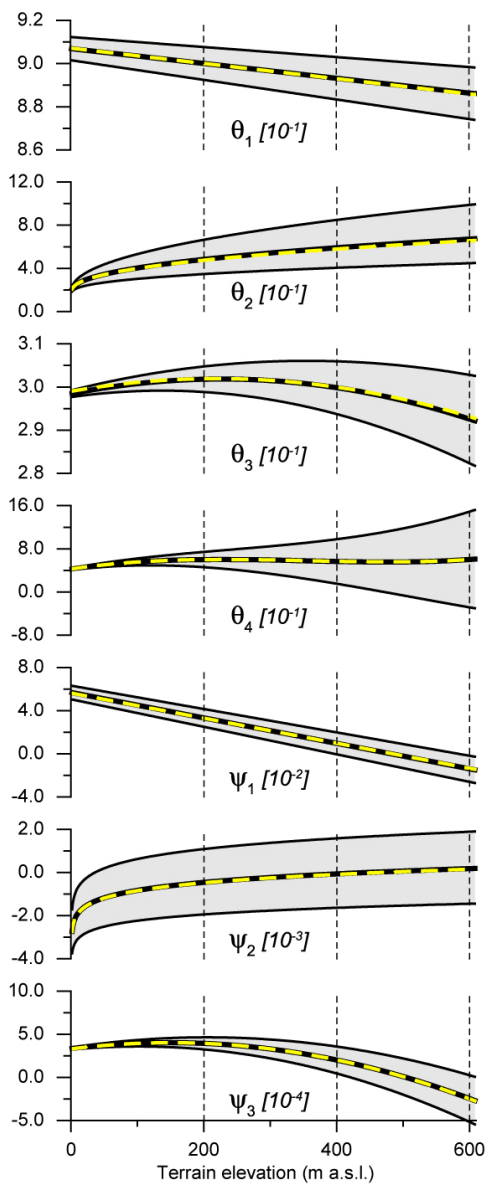

Fig. 3. Parameter functions $\theta_{1-4}(z)$ and $\psi_{1-3}(z)$ of the albedo model according to Table 2 . The broken yellow lines represent the functions of the IAM. The solid black lines and the grey uncertainty ranges represent the functions of the FAM. For better comparability, all parameter functions are displayed in the same order of magnitude. The conversion factor to the original values is given in italic brackets behind the parameter symbol of each graph.

The sigmoid function of rain-snow ratio $\left(\Theta_{i}(z)\right)$ for any of the 31 elevation bins characterized by its mean terrain elevation $z$ is given as

$\Theta_{i}(z)=\frac{\theta_{1}(z)-\theta_{2}(z)}{1+\left(\frac{\Phi_{\mathrm{rS} r i}(z)}{\theta_{3}(z)}\right)^{\theta_{4}(z)}}+\theta_{2}(z)$.

It is fitted to the whole set of the 64 monthly data pairs of rain-snow ratio and surface albedo that represent terrain elevation $z$. Thus, the parameters $\theta_{1-4}$ are obtained individually for each of the 31 elevation bins. As they show systematic variability with terrain elevation, continuous parameter functions $\theta_{1-4}(z)$ can be derived by fitting either linear, polynomial or exponential functions of terrain elevation $z$ to these individual values. Figure 3 and Table 2 give an overview of the fitted parameter functions and their coefficients of determination. Figure 2 presents the fitted sigmoid functions of rain-snow ratio, Eq. (10), for three selected bins and therewith illustrates their altitudinal variability. The residuals that remain after the sigmoid approximation are then fitted using multiple linear regression based on the independent variables cumulative snowfall and cumulative positive degree days since the beginning of the corresponding mass-balance year, i.e. the previous September. The linear function of cumulative snowfall and cumulative positive degree days $\left(\Psi_{i}(z)\right)$ for any $20 \mathrm{~m}$ bin with mean terrain elevation $z$ is given as

$\Psi_{i}(z)=\psi_{1}(z)+\psi_{2}(z) \Phi_{\mathrm{csf}, i}(z)+\psi_{3}(z) \Phi_{\mathrm{cpdd}, i}(z)$.

It is likewise fitted to the whole set of 64 months of input data and continuous parameter functions $\psi_{1-3}(z)$ are derived (Fig. 3, Table 2). The albedo-profile model calibrated in this manner is termed the initial albedo model (IAM).

For assessment of the accuracy of the IAM, modelled albedo profiles of all 64 months are compared to the ones derived from the MOD10A1 data. For each profile the RMSE and the mean difference is calculated over the set of all 31 individual albedo values that correspond to the respective $20 \mathrm{~m}$ elevation bins. Figure 4 presents an overview of the temporal distribution of the individual RMSE and mean differences over the calibration period. Overall, the accuracy assessment yields a mean RMSE of $0.055 \pm 0.026$ with a slightly lower median of 0.052 . The majority of all RMSE lies in the range $0.03-0.07$. The mean difference amounts to $-0.004 \pm 0.047$ with a median of -0.005 . Neither the RMSE nor the mean differences show any considerable, systematic temporal evolution. Indeed the mean monthly RMSE increase towards the end of the mass balance year (Fig. 4) but the corresponding mean differences are still close to zero and only show a larger spread. An elevation-dependent bias between modelled and observed albedo values does only exist at terrain elevations above $500 \mathrm{~m}$ a.s.l. (Fig. 5). This documents a generally good model performance over most parts of the ice cap and over the entire annual cycle.

However, the calibration of the parameter functions $\theta_{1-4}(z)$ and $\psi_{1-3}(z)$ of the IAM employs data of all 64 months available, i.e. calibration and application period of the model are identical. It can thus only serve as an optimum reference of model performance as no independent validation is possible. In order to present an albedo model that is applicable not only in the reference period, calibration and implicit validation of the final model is done using a cross validation-based procedure.

\subsection{Calibration and cross-validation}

The final albedo model (FAM) is calibrated using k-folds cross-validation techniques (Kohavi, 1995). This means that the sample of the 64 different monthly albedo profiles is divided into $k=8$ annual subsets. The described calibration procedure of $\theta_{1-4}(z)$ and $\psi_{1-3}(z)$ is then repeated $k$ times. Each time, all data of a specific year $k$ are left out and the parameter functions are fitted to the reduced set of input data 

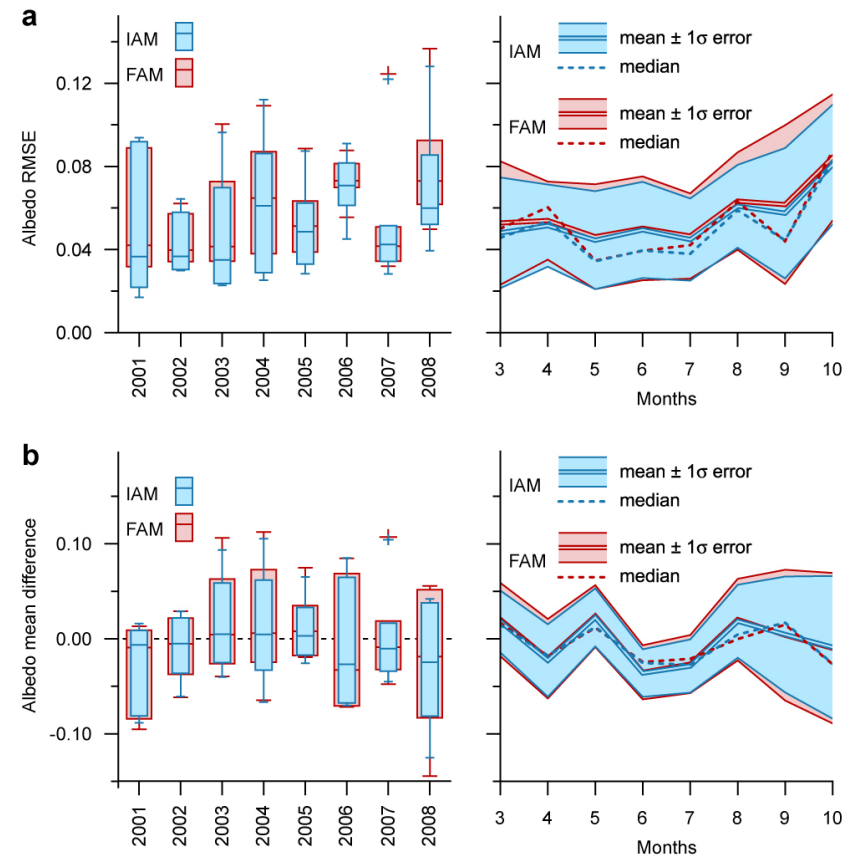

Fig. 4. Mean deviations between MODIS-observed albedo and albedo modelled using the IAM (bluish) and the FAM (reddish). Deviations are expressed as (a) root mean square error (RMSE) and (b) mean difference. The box plots (left) present the annual subdivision according to the $\mathrm{k}$-folds cross-validation. The boxes spread between lower and upper quartiles of the sample with the median shown as the line in between, the whiskers extend the boxes by 1.5 times the inter quartile range. Values outside this range (cross symbols) are considered as outliers. The line graphs (right) present the temporal evolution of the deviations on the monthly time scale.

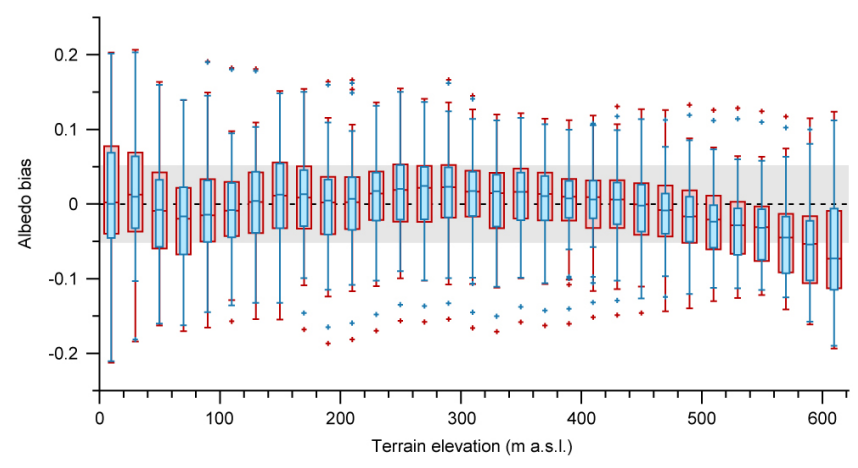

Fig. 5. Profile of biases between MODIS-derived albedo values and albedo values modelled using the IAM (blueish) and the FAM (reddish). Data are based on the monthly values of the period MarchOctober of the years 2001-2008. A positive bias signifies an overestimation of albedo by the model and a negative bias an underestimation. The grey shading represents the overall median RMSE of the FAM (0.054). Box plots are designed as in Fig. 4. representing 56 instead of 64 months. By doing so, a model is build that provides the possibility for an independent validation of its one-year application period. This is because the model is capable of calculating the albedo profile of year $k$ without using any input data of this very year for calibration. From the resulting eight individual model calibrations (Fig. 6), the means of each of the 20 individual parameters of the seven parameter functions (Table 2) are calculated. They serve as the final parameters of the FAM. The ranges of uncertainty of the parameter functions (Fig. 3) that result from the associated standard deviations of the means (Table 2) are discussed as part of the sensitivity studies.

In recent years this special kind of model calibration was introduced to glaciological studies (e.g. Hofer et al., 2010; Marzeion et al., 2012). However, distinctly larger sample sizes and different cross-validation methods, i.e. movingblocks and leave-one-out cross-validation, set these studies apart from the here presented application. The specific type of autocorrelation that is present in glacier-surface albedo time series prohibits the usage of these methods. The albedo evolution within each mass balance year can be considered to be decorrelated from the previous mass balance year. Surface albedo returns to similar initial condtions during the winter snowfall. Afterwards, the albedo evolution is then only governed by contemporaneous weather influences until bare-ice exposure occurs. These characteristics suggest the usage of a k-folds cross-validation as the albedo-profile sample has to be divided into annual subsets (the folds) to create independent training and validation datasets.

The accuracy assessment of the FAM is again based on the mean RMSE values and mean differences between modelled and observed albedo profiles along the 31 elevations bins of each profile. In general, the resulting RMSE values for all 64 different months are very similar to the ones resulting from calculations using the IAM (Fig. 4). Small differences with slightly higher mean monthly RMSE indeed occur but never exceed values of 0.01 , i.e. one albedo percent. Accordingly, the calibration and cross-validation of the FAM results in a mean RMSE of $0.057 \pm 0.028$ with a slightly lower median of 0.054 . The mean difference is $-0.003 \pm 0.053$ with a median of -0.004 , which is even slightly closer to zero than in case of the IAM. Also the temporal evolution of the albedo deviations of the FAM is similar to that one of the IAM (Fig. 4).

The influence of the albedo error on net shortwave radiation and thus on available melt energy at the glacier surface is, however, predominantly controlled by the annual solar-radiation cycle (Table 3). As a consequence, the increase of model RMSE towards the end of a mass balance year does not imprint on melt energy. The largest albedoerror induced RMSE in net shortwave radiation flux occur in the summer months but never exceed $17.0 \mathrm{~W} \mathrm{~m}^{-2}$. During the ablation season at Vestfonna, i.e. June to August (Möller et al., 2011a), the albedos modelled using the FAM underestimate the MODIS-derived albedos by 0.035 at the maximum (Table 3). This leads to an overestimation of the 
Table 3. Mean monthly deviations between MODIS-observed albedo and albedo modelled using the FAM and the resulting deviations in net shortwave radiation flux at the glacier surface. Deviations are expressed as both root mean square error (RMSE) and mean difference. The monthly mean potential solar radiation fluxes are calculated using standard solar geometry algorithms (Möller et al., 2011a) and refer to a latitude of $80^{\circ} \mathrm{N}$. The mean values are given with a \pm one standard deviation range.

\begin{tabular}{crrrrr}
\hline \multirow{2}{*}{ Month } & Potential solar radiation $\left(\mathrm{W} \mathrm{m}^{-2}\right)$ & \multicolumn{2}{c}{ Albedo } & \multicolumn{2}{c}{ Net sw radiation $\left(\mathrm{W} \mathrm{m}^{-2}\right)$} \\
& & RMSE & Mean difference & RMSE & Mean difference \\
\hline Mar & 25.1 & 0.053 & 0.020 & 1.3 & -0.5 \\
Apr & 127.3 & 0.054 & -0.021 & 6.9 & 2.7 \\
May & 264.8 & 0.046 & 0.024 & 12.2 & -6.4 \\
Jun & 339.1 & 0.050 & -0.035 & 17.0 & 11.9 \\
Jul & 301.7 & 0.046 & -0.027 & 13.9 & 8.1 \\
Aug & 175.8 & 0.063 & 0.020 & 11.1 & -3.5 \\
Sep & 51.7 & 0.062 & 0.004 & 3.2 & -0.2 \\
Oct & 2.2 & 0.084 & -0.010 & 0.2 & 0.0 \\
Mean & $161.0 \pm 130.5$ & $0.057 \pm 0.013$ & $-0.003 \pm 0.023$ & $8.2 \pm 6.2$ & $1.5 \pm 6.0$ \\
\hline
\end{tabular}

mean melt-energy flux during the ablation season of just $5.5 \mathrm{~W} \mathrm{~m}^{-2}$ when averaged over the ice cap. Considering the frequent cloud cover (Möller et al., 2011a), this value is even more reduced in reality.

The profiles of the remaining biases of IAM and FAM are likewise similar (Fig. 5). The FAM profile indeed shows a slightly wider spread for the values of all individual elevation bins, but the overall bias pattern appears to be the same for both IAM and FAM. No systematic elevation-dependency is obvious except for an increasing underestimation in the uppermost parts of the ice cap above $500 \mathrm{~m}$ a.s.l. (Fig. 5).

As the presented albedo model is intended for application in glacier melt models the above outlined deviations can be regarded as acceptable drawbacks. The induced errors in available melt energy (Table 3) are mainly based on the negative albedo bias in the upper parts of the ice cap. Hence, the potentially resulting errors in melt modelling are mainly limited to regions where only very little ablation occurs and can, moreover, anyway be considered to be of minor magnitude (Möller et al., 2011a). Taken together, this reveals a good and reliable performance of the FAM in view of its intended application.

\subsection{Sensitivity studies}

Calibration and cross-validation of the FAM revealed a spread of possible model parameters (Fig. 6) that suggests considerable sensitivity towards the choice of which parameter calibration is used. Differences of more than one order of magnitude are evident in the relative variability within the 8 -samples sets of different calibrations of each model parameter. This means that the cross-validation procedure resulted in very stable calibrations of some of the model parameters (e.g. $\theta_{1} b, \theta_{3} a$ or $\psi_{3} a$ ) while others show distinctly weaker calibrations (e.g. $\theta_{1} a, \theta_{3} c$ or $\theta_{4} d$ ).

The influence of the parameter spreads on modelled albedo is assessed within the range of one standard deviation of each of the seven parameter functions shown in Fig. 3. The FAM is run two times for each parameter function (mean plus one standard deviation and mean minus one standard deviation). For each of the $3120 \mathrm{~m}$ elevation bins, the resulting maximum deviation from the albedo values modelled by the unchanged FAM is then taken as model sensitivity. Figure 7 presents an overview of the individual model sensitivities regarding all seven parameter functions.

Results indicate a minor model sensitivity regarding most parameter functions. The vast majority of albedo deviations lies below 0.01 , i.e. one albedo percent, for individual elevation bins. Moreover, for the albedo deviations of most parameter functions, no interannual variability or variability over the range of albedo values is evident.

The albedo deviations of three parameter functions $\left(\theta_{2}\right.$, $\theta_{4}$ and $\psi_{2}$ ) differ significantly from this overall pattern. $\theta_{2}$ shows mean sensitivities of up to 0.08 without any considerable variation. Sensitivities of $\theta_{4}$ exceed 0.20 during the spring and autumn months at high albedo values. However, during the ablation season, i.e. June to August, they are still in line with the overall pattern and show only minor values of less than 0.01 over the entire range of albedo values.

The most extreme sensitivity of the FAM towards its model parameters results from a variation of $\psi_{2}$ (Fig. 7). Introduced albedo deviations show a partly comparable pattern as for $\theta_{2}$ but with distinctly amplified values. In summer, at low albedo values they reach more than 0.05 , while at high albedo values they even exceed 0.55 . Moreover, the albedo deviations experience a clear increase with time between September and the following August. This is because of the fact that $\psi_{2}$ is the regression coefficient associated with the input variable cumulative snowfall sum, Eq. (11). As the values of this input variable constantly increase until August of each year, a variation of its regression coefficient results in likewise increased albedo deviations. However, the extremely high sensitivity of the FAM towards $\psi_{2}$ can partly be explained as a model artefact. The parameter function 


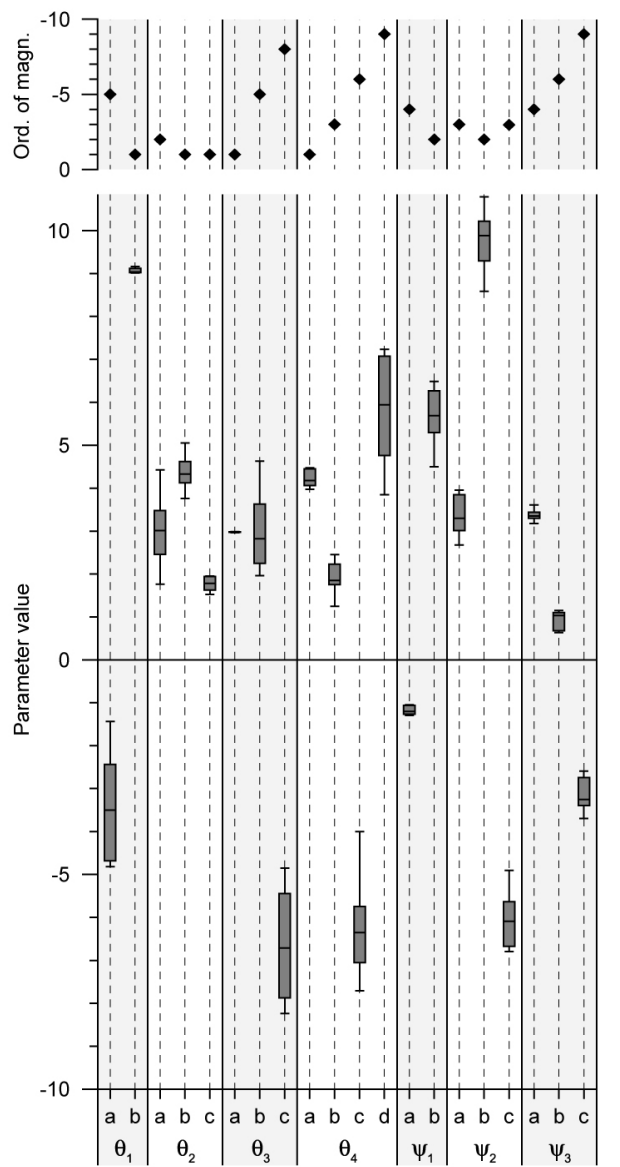

Fig. 6. Parameters of the parameter functions $\theta_{1-4}(z)$ and $\psi_{1-3}(z)$ of the albedo model as resulting from the cross-validation (lower graph). Box plots are created on the basis of the 8 individual model calibrations and are designed as in Fig. 4. For better comparability, all parameters are displayed in the same order of magnitude. The conversion factors to the original values are shown in the upper graph.

develops very close to zero above $\sim 200 \mathrm{~m}$ a.s.l. (Fig. 3). As a result, small perturbations of the parameters ( $a, b$ and $c$ ) of $\psi_{2}$ (Table 2) already result in large relative variations of $\psi_{2}$ itself. This, in turn, blows up the variability of modelled albedo after a winter season due to multiplication of $\psi_{2}$ with a high value of $\Phi_{\mathrm{csf}, i}$, Eq. (11).

The profile of overall model sensitivity, i.e. the summed up albedo deviation $\Delta \alpha_{\text {all }}(z)$, is calculated from the seven individual sets of albedo deviations $\left(\Delta \alpha_{p}(z)\right)$ as presented in Fig. 7 using error propagation rules according to

$\Delta \alpha_{\text {all }}(z)=\sqrt{\sum_{p} \Delta \alpha_{p}(z)^{2}}$ with $p=\theta_{1-4}$ and $\psi_{1-3}$.

Results (Fig. 8) reflect the predominant influence of albedo deviations introduced by sensitivity towards variations of $\psi_{2}$ and thus show a similar spatiotemporal pattern. Albedo deviations increase with terrain elevation, i.e. towards higher
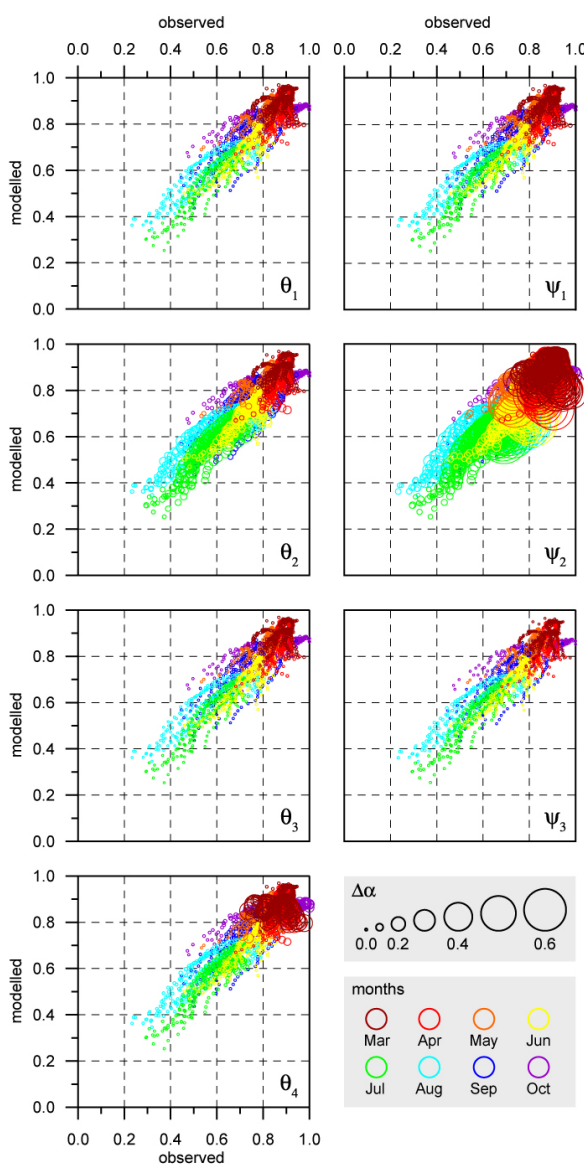

Fig. 7. Sensitivity of modelled albedo values towards variations of the individual parameter functions $\theta_{1-4}(z)$ and $\psi_{1-3}(z)$ of the FAM (given in the lower right corner of each graph) shown as scatter plots between observed and modelled albedo values. The size of the circles indicate the magnitude of sensitivity, i.e. of albedo deviation $(\Delta \alpha)$. The colour of the circles indicate the associated month. Given albedo deviations reflect the model sensitivity within the \pm one standard deviation uncertainty ranges of the parameter functions (Fig. 3).

albedo values, and show a superimposed increase over the year until summer followed by a sudden drop to significantly lower values in September.

\subsection{Discussion and error assessment}

The altitudinal variability of the model parameters as it is represented in the seven parameter functions (Fig. 3) indicates that the surface-albedo pattern of Vestfonna is not only governed by the set of meteorological variables employed in this study. If these were the exclusive predictors of surface albedo, the parameters should be fairly constant over terrain elevation. Hence, additional driving forces for surface-albedo variations must exist.

It is suggested that the altitudinal variability of the model parameters represents a superimposition of in-situ conditions 

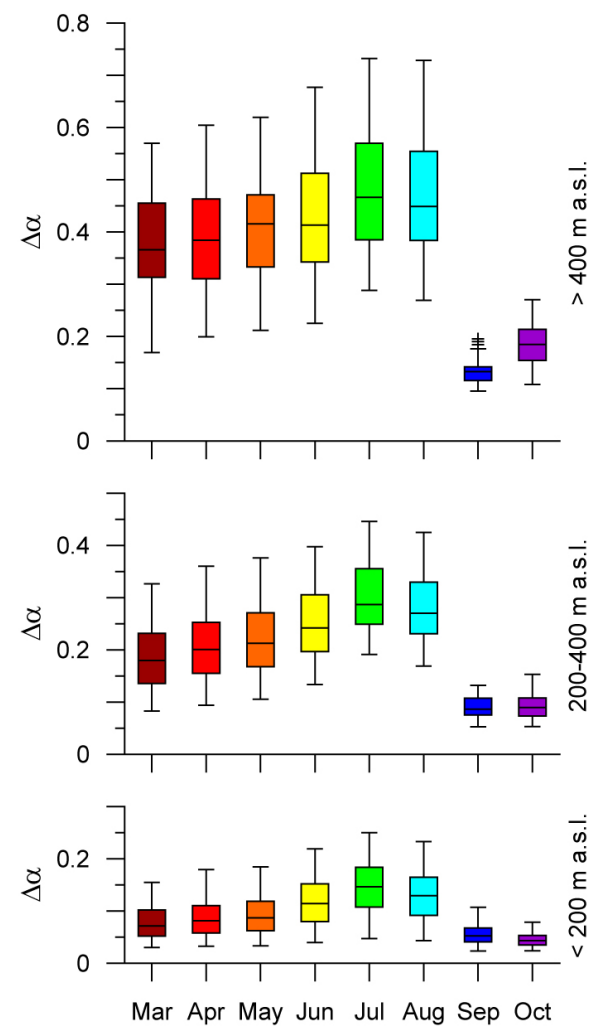

Fig. 8. Overall sensitivity of modelled albedo values towards mutual variations of all parameter functions of the FAM according to Eq. (12). Given albedo deviations $(\Delta \alpha)$ reflect the model sensitivity within the \pm one standard deviation uncertainty ranges of the parameter functions (Fig. 3). Box plots are created from data of a specific subset of terrain elevations given at the right of each graph. They are designed as in Fig. 4, the colour code corresponds to Fig. 7. Data are based on the period March-October of the years 20012008.

(as they are created by the considered meteorological variables) by snowdrift influences (cf. Sect. 4.1 Fundamentals). According to Sauter (personal communication) radial snowdrift trajectories are a common pattern on Vestfonna due to katabatic winds. Hence, it is reasonable to assume that the disturbance of in situ-developed surface-albedo conditions due to snowdrift also shows a strong altitude dependency.

The fact that the remaining bias of modelled albedo values is largest throughout the uppermost parts of the profile (Fig. 5) is also based on snowdrift influences even if these are already accounted for during model calibration. This apparent contradiction can be explained by wind influences of different origin. Whereas radially directed katabatic winds dominate throughout the slopes of the ice cap (Claremar et al., 2012), the uppermost parts of the ice cap can be expected to be predominantly influenced by synoptic winds. Hence, snowdrift trajectories along the exposed ridges show a distinctly higher variability as they do throughout the slopes. This characteristic cannot be captured entirely by the
Table 4. Parameters of the error function of the FAM, Eq. (13).

\begin{tabular}{cr}
\hline Parameter & Value \\
\hline$\epsilon_{1}$ & $7.52 \times 10^{-12}$ \\
$\epsilon_{2}$ & $-8.29 \times 10^{-9}$ \\
$\epsilon_{3}$ & $3.01 \times 10^{-6}$ \\
$\epsilon_{4}$ & $-4.35 \times 10^{-4}$ \\
$\epsilon_{5}$ & $7.89 \times 10^{-2}$ \\
\hline
\end{tabular}

elevation-dependent setup of the minimal albedo model presented in this study.

Accordingly, these upper parts of the ice cap where high albedo values prevail throughout the entire year are also the regions where critical model sensitivities are reached. However, the final calibration of the FAM shows no considerable differences to that one of the IAM in terms of parameter functions (Fig. 3, Table 2) and the IAM is assumed to be the optimum reference of model performance (cf. Sect. 4.2 Initial setup). Thus, the albedo profiles modelled by the FAM are considered as reliable despite the high model sensitivities at high albedo values.

The accuracy of the albedo values modelled by the FAM shows strong variability with terrain elevation (Fig. 5). This is also reflected in the associated RMSE profile (Fig. 9) that is calculated on the basis of the bias profile of the FAM (Fig. 5). In comparison with the area-altitude distribution of Vestfonna (Fig. 9) this pattern of altitudinal variability of the RMSE reveals that an area-weighting slightly reduces the mean RMSE to 0.054 . This is because lowest RMSE values along the profile are associated with the interval of most frequent terrain elevations ( $400-550 \mathrm{~m}$ a.s.l.). Highest RMSE values, in contrast, are limited to terrain elevations covering distinctly smaller areas. Terrain elevations below $50 \mathrm{~m}$ a.s.l. are only reached at the lowermost parts of the outlet-glacier tongues while elevations higher than $550 \mathrm{~m}$ a.s.l. only exist along the main ridges of the ice cap.

For any further usage of the FAM, e.g. in mass balancemodelling studies, an exactly quantifiable error range needs to be defined. Owing to the facts discussed before, this error range $(E(z))$ is expressed as a function of terrain elevation according to the RMSE profile of the models (Fig. 9) rather than as a constant value. Therefore, RMSE values for each elevation bin are calculated on the basis of the bias profile of the FAM (Fig. 5). Afterwards they are fitted by a fourth-order polynomial according to

$E(z)=\epsilon_{1}+\epsilon_{2} \times z+\epsilon_{3} \times z^{2}+\epsilon_{4} \times z^{3}+\epsilon_{5} \times z^{4}$.

The parameter values $\epsilon_{1-5}$ are given in Table 4 . The fitted function allows for an almost perfect reproduction of the RMSE profile $\left(R^{2}=0.98\right)$ and is thus regarded as a reliable expression of model error. Accordingly, the overall formulation of the FAM that is suitable for further usage in broader 


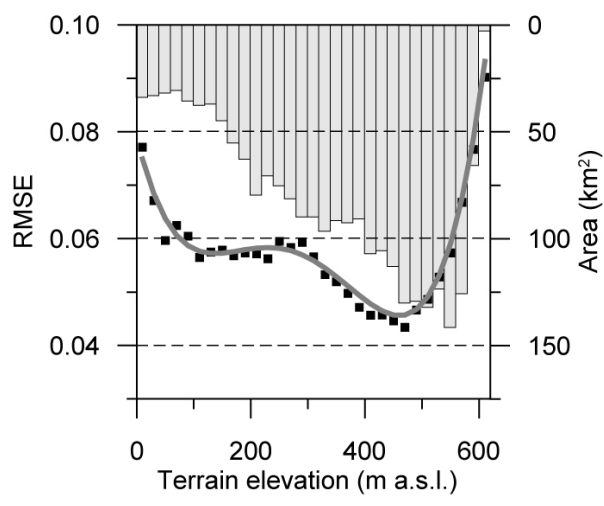

Fig. 9. Error range of the FAM expressed as 4th-order polynomial function of terrain elevation (grey line). The function is fitted to the profile of RMSE between observed and modelled albedo values (black symbols). Given data pairs refer to the period MarchOctober of the years 2001-2008. The bar chart shows the areaaltitude distribution of Vestfonna ice cap.

modelling applications is given as

$\alpha_{i}(z)=\left(\Theta_{i}(z)-\Psi_{i}(z)\right) \pm E(z)$.

This final error range, however, still does not account for the limitations of the model regarding an application under past or future conditions that are induced by the inevitable assumption of stationarity of present boundary conditions. Indeed the general pattern of curvature and wind exposure can be expected to be similar on a larger or smaller ice cap as the dome-like shape of Vestfonna would be remained until it starts to disintegrate due to bedrock influences. And indeed, the pattern of snowdrift influences that is assumed to largely determine the variability of model error with elevation would thus not change considerably over a shrinking or extending ice cap. However, it has to be born in mind that this implicitly made assumption of stationarity might nevertheless result in non-quantifiable errors. This has to be accounted for when applying the albedo-modelling scheme in mass balance studies with non-present boundary conditions by discussing the potentially induced uncertainties.

\section{Conclusions}

A new, statistical albedo model is presented in this study. The model is developed and applied at Vestfonna ice cap in northeastern Svalbard and intended for further usage within broader, especially long-term energy or mass-balance calculations. It calculates the mean altitudinal albedo profile of the ice cap on a monthly resolution using a minimal set of meteorological variables as input. The surface albedo fields used for calibration and cross-validation purposes are taken from the daily MODIS snow product MOD10A1. The meteorological record used is based on daily ERA-Interim data of a grid point located close to the south of the ice cap. Modelling is done for the years 2001-2008 excluding the winter months, i.e. in the period March to October, due to missing MODIS data during polar night. The model architecture is based on a calculation scheme that combines a sigmoid function of rain-snow ratio with a linear function of cumulative snowfall and cumulative positive degree days. The artificial quantity rain-snow ratio was developed in order to combine the varying influences of air temperature, rainfall and snowfall on the actual snow cover into one meaningful variable. Snowdrift influences on surface albedo are implicitly accounted for by the model.

Validation of the final albedo model reveals a good model performance over large parts of the altitudinal profile of the ice cap. Modelled and observed albedo values along the profile differ with an RMSE of $0.057 \pm 0.028$ (mean \pm one standard deviation) and an area weighted mean of 0.054. Terrain elevations that show higher RMSE values $(0.07-0.09)$ are limited to the lower- and uppermost parts of the ice cap and thus to regions that either cover very limited areas or are hardly affected by surface melt. Throughout terrain elevations that are most frequent on Vestfonna, the RMSE even drops to values well below 0.05 . In the period of peak melting, i.e. in July (Möller et al., 2011a), the RMSE is also below 0.05 . Hence, the calculated albedo profiles are regarded as reliable reproduction of in-situ conditions in the context of further model application in broader, ice cap-wide energy or mass-balance studies. The presented albedo model is therefore suggested to be fully suitable for this purpose.

Acknowledgements. This study was funded by grants No. SCHN680/2-2 of the German Research Foundation (DFG) and 03F0623B of the German Federal Ministry of Education and Research (BMBF). All ERA-Interim data used are provided by the European Centre for Medium-Range Weather Forecasts (ECMWF). Tobias Sauter is acknowledged for annotations on an earlier version of the manuscript. Two anonymous reviewers provided important comments that helped to improve the manuscript.

Edited by: M. Van den Broeke

\section{References}

Ahlmann, H.: Scientific results of the Swedish-Norwegian Arctic Expedition in the summer of 1931. Part VIII - Glaciology, Geogr. Ann., 15, 161-216, 1933.

Arendt, A.: Approaches to modelling the surface albedo of a High Arctic glacier, Geogr. Ann., 81A, 477-487, 1999.

Beaudon, E., Arppe, L., Jonsell, U., Martma, T., Möller, M., Pohjola, V., Scherer, D., and Moore, J.: Spatial and temporal variability of net accumulation from shallow cores from Vestfonna ice cap (Nordaustlandet, Svalbard), Geogr. Ann., 93A, 287-299, 2011.

Braithwaite, R.: Calculation of degree-days for glacier-climate research, Z. Gletscherk. Glazialgeol., 20, 1-8, 1984.

Braun, M., Pohjola, V., Pettersson, R., Möller, M., Finkelnburg, R., Falk, U., Scherer, D., and Schneider, C.: Changes of glacier 
frontal positions of Vestfonna (Nordaustlandet, Svalbard), Geogr. Ann., 93A, 301-310, 2011.

Brock, B., Willis, I., and Sharp, M.: Measurements and parameterization of albedo variations at Haut Glacier d'Arolla, Switzerland, J. Glaciol., 46, 675-688, 2000

Claremar, B., Obleitner, F., Reijmer, C., Pohjola, V., Waxegård, A., Karner, F., and Rutgersson, A.: Applying a mesoscale atmospheric model to Svalbard glaciers, Adv. Meteorol., 321649, doi:10.1155/2012/321649, 2012.

Essery, R., Blyth, E., Harding, R., and Lloyd, C.: Modelling albedo and distributed snowmelt across a low hill in Svalbard, Nord. Hydrol., 36, 207-218, 2005.

Førland, E., Hanssen-Bauer, I., and Nordli, P.: Climate Statistics and Longterm Series of Temperatures and Precipitation at Svalbard and Jan Mayen, Det Norske Meteorologiske Institutt, Oslo, 1997.

Hagen, J., Liestøl, O., Roland, E., and Jørgensen, T.: Glacier Atlas of Svalbard and Jan Mayen, Meddelelser Nr. 129, Norsk Polarinstitutt, Oslo, 1993.

Hall, D. and Riggs, G.: Accuracy assessment of the MODIS snow products, Hydrol. Process., 21, 1534-1547, 2007.

Hall, D., Riggs, G., Salomonson, V., DiGirolamo, N., and Bayr, K.: MODIS snow-cover products, Remote Sens. Environ., 83, 181194, 2002

Hofer, M., Mölg, T., Marzeion, B., and Kaser, G.: Empiricalstatistical downscaling of reanalysis data to high-resolution air temperature and specific humidity above a glacier surface (Cordillera Blanca, Peru), J. Geophys. Res., 115, D12120, doi:10.1029/2009JD012556, 2010.

Huth, R.: Statistical downscaling in central Europe: Evaluation of methods and potential predictors, Clim. Res., 13, 91-101, 1999.

Jordan, R., Albert, M., and Brun, E.: Physical processes within the snow cover and their parameterization, in: Snow and Climate, Physical Processes, Surface Energy Exchange and Modeling, edited by: Armstrong, R. and Brun, E., Cambridge University Press, Cambridge, 12-69, 2008.

Karl, T., Wang, W., Schlesinger, M., Knight, R., and Portman, D.: A method of relating general circulation model simulated climate to observed local climate. Part I: Seasonal statistics, J. Climate, 3, 1053-1079, 1990.

Kaser, G., Cogley, J., Dyurgerov, M., Meier, M., and Ohmura, A.: Mass balance of glaciers and ice caps: Consensus estimates for 1961-2004, Geophys. Res. Lett., 33, L19501, doi:10.1029/2006GL027511, 2006.

Kohavi, R.: A study of cross-validation and bootstrap for accuracy estimation and model selection, in: Proceedings of the 14th International Joint Conference on Artificial Intelligence, edited by: Mellish, C., Morgan Kaufmann, San Francisco, 1137-1143, 1995.

Loeng, H.: Features of the physical oceanographic conditions of the Barents Sea, Polar Res., 10, 5-18, 1991.

Mahesh, A., Eager, R., Campbell, J., and Spinhirne, J.: Observations of blowing snow at the South Pole, J. Geophys. Res., 108, D04707, doi:10.1029/2002JD003327, 2003.

Marzeion, B., Hofer, M., Jarosch, A. H., Kaser, G., and Mölg, T.: A minimal model for reconstructing interannual mass balance variability of glaciers in the European Alps, The Cryosphere, 6, 71-84, doi:10.5194/tc-6-71-2012, 2012.

Möller, M. and Schneider, C.: Calibration of glacier volume-area relations from surface extent fluctuations and application to future glacier change, J. Glaciol., 56, 33-40, 2010

Möller, M., Finkelnburg, R., Braun, M., Hock, R., Jonsell, U., Pohjola, V., Scherer, D., and Schneider, C.: Climatic mass balance of Vestfonna ice cap, Svalbard: A spatially distributed assessment using ERA-Interim and MODIS data, J. Geophys. Res., 116, F03009, doi:10.1029/2010JF001905, 2011a.

Möller, M., Möller, R., Beaudon, E., Mattila, O.-P., Finkelnburg, R., Braun, M., Grabiec, M., Jonsell, U., Luks, B., Puczko, D., Scherer, D., and Schneider, C.: Snowpack characteristics of Vestfonna and DeGeerfonna (Nordaustlandet, Svalbard) - a spatiotemporal analysis based on multiyear snow-pit data, Geogr. Ann., 93A, 273-285, 2011b.

Moss, R.: The physics of an ice cap, Geogr. J., 92, 211-231, 1938.

Raper, S. and Braithwaite, R.: Low sea level rise projections from mountain glaciers and ice caps under global warming, Nature, 439, 311-313, 2006.

Rinke, A. and Dethloff, K.: Simulated circum-Arctic climate changes by the end of the 21st century, Glob. Planet. Change, 62, 173-186, 2008.

Rotschky, G., Schuler, T., Haarpaintner, J., Kohler, J., and Isaksson, E.: Spatio-temporal variability of snowmelt across Svalbard during the period 2000-08 derived from QuikSCAT/SeaWinds scatterometry, Polar Res., 30, 5963, doi:10.3402/polar.v30i0.5963, 2011.

Schaaf, C., Wang, Z., and Strahler, A.: Commentary on Wang and Zender - MODIS snow albedo bias at high solar zenith angles relative to theory and to in situ observations in Greenland, Remote Sens. Environ., 115, 1296-1300, 2011.

Stroeve, J., Box, J., and Haran, T.: Evaluation of the MODIS (MOD10A1) daily snow albedo product over the Greenland ice sheet, Remote Sens. Environ., 105, 155-171, 2006.

Svendsen, H., Beszczynska-Møller, A., Hagen, J., Lefauconnier, B., Tverberg, V., Gerland, S., Ørbæk, J., Bischof, K., Papucci, C., Zajaczkowski, M., Azzolini, R., Bruland, O., Wiencke, C., Winther, J.-G., and Dallmann, W.: The physical environment of Kongsfjorden-Krossfjorden, an Arctic fjord system in Svalbard, Polar Res., 21, 133-166, 2002.

Taurisano, A., Schuler, T., Hagen, J., Eiken, T., Loe, E., Melvold, K., and Kohler, J.: The distribution of snow accumulation across the Austfonna ice cap, Svalbard: direct measurements and modelling, Polar Res., 26, 7-13, 2007.

Von Storch, H.: On the use of "inflation" in statistical downscaling, J. Climate, 12, 3505-3506, 1999.

Walczowski, W. and Piechura, J.: Influence of the West Spitsbergen Current on the local climate, Int. J. Climatol., 31, 1088-1093, 2011.

Wang, X. and Zender, C.: Constraining MODIS snow albedo at large zenith angles: Implications for the surface energy budget of Greenland, J. Geophys. Res., 115, F04015, doi:10.1029/2009JF001436, 2010a.

Wang, X. and Zender, C.: MODIS snow albedo bias at high solar zenith angles relative to theory and to in situ observations in Greenland, Remote Sens. Environ., 114, 563-575, 2010b.

Winther, J.-G., Bruland, O., Sand, K., Gerland, S., Marechal, D., Ivanov, B., Głowacki, P., and König, M.: Snow research in Svalbard - an overview, Polar Res., 22, 125-144, 2003.

Wiscombe, W. and Warren, S.: A Model for the spectral albedo of snow. I: Pure snow, J. Atmos. Sci., 37, 2712-2733, 1980. 